\title{
The isotope bone scan: we can do better
}

\author{
Ignac Fogelman • Glen M. Blake • \\ Gary J. R. Cook
}

Received: 15 April 2013 / Accepted: 18 April 2013 /Published online: 15 May 2013

(C) Springer-Verlag Berlin Heidelberg 2013

The conventional isotope bone scan using ${ }^{99 \mathrm{~m}}$ Tc-labelled diphosphonate is perceived as being highly sensitive but non-specific in the detection of skeletal pathology. The poor specificity is a significant clinical issue, as additional investigations are frequently required (X-ray, CT, MRI) to clarify equivocal lesions, such as the presence of degenerative changes, where metastatic involvement is suspected. This inevitably leads to extra cost, heightened concern and frequent delays in management. Where available, specificity (and to a lesser extent sensitivity) has been greatly improved with the use of single photon emission computed tomography $(\mathrm{SPECT}) / \mathrm{CT}[1-3]$, but can be further significantly improved with the use of ${ }^{18} \mathrm{~F}$-fluoride positron emission tomography (PET)/CT [4-6]. Further, ${ }^{18}$ F-fluoride can on occasion identify early metastatic lesions at a time when the bone scan is normal [7-10]. Nevertheless, ${ }^{18} \mathrm{~F}$-fluoride is rarely used routinely for bone imaging due to the limited availability of PET, cost and competition for time on the PET scanner.

In addition to the above issues there are significant limitations to the use of the bone scan for its most common application, the detection and assessment of metastatic disease. A

\section{Fogelman · G. M. Blake}

King's College London, Department of Nuclear Medicine,

King's College Academic Health Partners,

Guy's Campus, Ground Floor, Borough Wing,

London SE1 9RT, UK

I. Fogelman

e-mail: ignac.fogelman@kcl.ac.uk

G. J. R. Cook

King's College London, PET Imaging Centre,

King's College Academic Health Partners, St Thomas' Campus,

London, UK

G. M. Blake $(\bowtie)$

Osteoporosis Unit, Guy's Hospital, 1st Floor, Tower Block,

London SE1 9RT, UK

e-mail: glen.blake@kcl.ac.uk frequent request is to monitor the effect of treatment, but it is well recognised that even with successful treatment there will be a significant delay before this becomes apparent on the bone scan due to ongoing altered metabolic activity in bone, and there is the possibility of a flare response if the study is performed too early. In the situation where there is such extensive skeletal involvement that lesions coalesce, effectively superficially 'normalising' appearances (the 'superscan' of malignancy), any change is likely to be difficult to detect and further, it is now apparent there may be significant alterations in the metabolic activity of individual lesions but with no apparent visual difference between studies [11]. In this situation quantitation is required to clarify the issue. Quantitation with a conventional bone scan is problematic and techniques that have been used in the past such as measuring bone to soft tissue or lesion to bone ratios are crude and nowadays rarely, if ever, performed. Quantitation is, however, routine with PET studies, and standardised uptake values (SUVs) are commonly measured using the 'universal' $\operatorname{tracer}{ }^{18} \mathrm{~F}$-fluorodeoxyglucose (FDG). As previously stated, ${ }^{18} \mathrm{~F}$-fluoride is not routinely used for bone scanning, although there are research reports demonstrating that SUVs can detect significant metabolic change in individual metastatic lesions even when visual evaluation reveals little if any difference [11].

In oncology there are a large number of new treatments that are either in development or have recently become available, and evaluating skeletal response is critical with regard to the future of a drug's development or to decide upon the optimal management of a patient. SUVs are satisfactory in most routine situations, although one must be aware of their limitations. Care must be taken with regard to quality control, for example if there is significant variation in the time when the scan is performed following injection, as this can impact on SUVs (generally there is increased uptake of tracer in a tumour with time). A more important limitation is that SUVs may not be accurate if skeletal involvement is so extensive that the arterial input function is altered, and in such situations 
true quantitation with tracer kinetic studies to measure skeletal plasma clearance is required $[12,13]$. Such studies are, however, complex and labour intensive and are not performed in routine practice. Nevertheless, there is considerable interest in tracer kinetic studies in the metabolic bone field and, in recent years, there have been significant developments that have simplified the methodology to the point where clinical use is becoming more feasible, and accurate measurements of ${ }^{18} \mathrm{~F}$ fluoride plasma clearance can be made at multiple sites throughout the skeleton from a single whole-body scan [14].

The isotope bone scan with ${ }^{99 \mathrm{~m}} \mathrm{Tc}-$ labelled diphosphonate is an old and trusted friend and continues to perform with some distinction. It is apparent, however, that we can do significantly better with ${ }^{18} \mathrm{~F}$-fluoride. In the field of oncology earlier identification of metastatic involvement is possible and, where it is important to assess whether a patient is responding to treatment, quantitation may provide such information $[11,15]$. As PET scanners are becoming more widely available there now appears to be a compelling case for the introduction of ${ }^{18} \mathrm{~F}$-fluoride as the 'new' bone scan into routine clinical practice.

The remaining questions are whether bone-specific tracers, such as ${ }^{18} \mathrm{~F}$-fluoride, or tumour-specific tracers, such as ${ }^{18} \mathrm{~F}$ FDG or ${ }^{11} \mathrm{C} /{ }^{18} \mathrm{~F}$-choline, are best suited in the different clinical applications of: (1) skeletal staging and (2) response assessment. It is possible that the high sensitivity of ${ }^{18} \mathrm{~F}$-fluoride PET is superior in the former and the high specificity of tumour-specific tracers in the latter [16, 17], although detecting early metastases in the bone marrow before an osteoblastic reaction may only be possible with tumourspecific tracers [16].

Whilst the addition of CT to both PET and SPECT scanners has undoubtedly improved diagnostic specificity in assessing skeletal metastases, the advent of PET/MRI may lead to increased sensitivity by detecting early bone marrow metastases, and may also improve the specificity of the assessment of response to treatment by the use of diffusion-weighted MR imaging [18].

\section{Conflicts of interest None.}

\section{References}

1. Horger M, Eschmann SM, Pfannenberg C, Vonthein R, Besenfelder $\mathrm{H}$, Claussen $\mathrm{CD}$, et al. Evaluation of combined transmission and emission tomography for classification of skeletal lesions. AJR Am J Roentgenol 2004;183:655-61.

2. Utsunomiya D, Shiraishi S, Imuta M, Tomiguchi S, Kawanaka K, Morishita S, et al. Added value of SPECT/CT fusion in assessing suspected bone metastasis: comparison with scintigraphy alone and nonfused scintigraphy and CT. Radiology 2006;238:264-71.
3. Helyar V, Mohan HK, Barwick T, Livieratos L, Gnanasegaran $\mathrm{G}$, Clarke SE, et al. The added value of multislice SPECT/CT in patients with equivocal bony metastasis from carcinoma of the prostate. Eur J Nucl Med Mol Imaging 2010;37:706-13.

4. Even-Sapir E, Metser U, Mishani E, Lievshitz G, Lerman H, Leibovitch I. The detection of bone metastases in patients with high-risk prostate cancer: $99 \mathrm{mTc}-\mathrm{MDP}$ planar bone scintigraphy, single- and multi-field-of-view SPECT, 18F-fluoride PET, and 18F-fluoride PET/CT. J Nucl Med 2006;47:287-97.

5. Even-Sapir E, Metser U, Flusser G, Zuriel L, Kollender Y, Lerman H, et al. Assessment of malignant skeletal disease: initial experience with $18 \mathrm{~F}$-fluoride PET/CT and comparison between $18 \mathrm{~F}$-fluoride PET and 18F-fluoride PET/CT. J Nucl Med 2004;45:272-8.

6. Krüger S, Buck AK, Mottaghy FM, Hasenkamp E, Pauls S, Schumann C, et al. Detection of bone metastases in patients with lung cancer: $99 \mathrm{mTc}-\mathrm{MDP}$ planar bone scintigraphy, $18 \mathrm{~F}$-fluoride PET or $18 \mathrm{~F}-\mathrm{FDG}$ PET/CT. Eur J Nucl Med Mol Imaging 2009;36:1807-12.

7. Hetzel M, Arslandemir C, König HH, Buck AK, Nüssle K, Glatting G, et al. F-18 NaF PET for detection of bone metastases in lung cancer: accuracy, cost-effectiveness, and impact on patient management. J Bone Miner Res 2003;18:2206-14.

8. Schirrmeister H, Glatting G, Hetzel J, Nüssle K, Arslandemir C, Buck AK, et al. Prospective evaluation of the clinical value of planar bone scans, SPECT, and (18)F-labeled NaF PET in newly diagnosed lung cancer. J Nucl Med 2001;42:1800-4.

9. Schirrmeister H, Guhlmann A, Kotzerke J, Santjohanser C, Kühn T, Kreienberg R, et al. Early detection and accurate description of extent of metastatic bone disease in breast cancer with fluoride ion and positron emission tomography. J Clin Oncol 1999;17:2381-9.

10. Schirrmeister H, Guhlmann A, Elsner K, Kotzerke J, Glatting G, Rentschler M, et al. Sensitivity in detecting osseous lesions depends on anatomic localization: planar bone scintigraphy versus 18F PET. J Nucl Med 1999;40:1623-9.

11. Cook Jr G, Parker C, Chua S, Johnson B, Aksnes AK, Lewington VJ. 18F-fluoride PET: changes in uptake as a method to assess response in bone metastases from castrate-resistant prostate cancer patients treated with 223Ra-chloride (Alpharadin). EJNMMI Res 2011;1:4.

12. Blake GM, Frost ML, Fogelman I. Quantitative radionuclide studies of bone. J Nucl Med 2009;50:1747-50.

13. Blake GM, Siddique M, Frost ML, Moore AE, Fogelman I. Radionuclide studies of bone metabolism: do bone uptake and bone plasma clearance provide equivalent measurements of bone turnover? Bone 2011;49:537-42.

14. Siddique M, Blake GM, Frost ML, Moore AE, Puri T, Marsden $\mathrm{PK}$, et al. Estimation of regional bone metabolism from wholebody 18F-fluoride PET static images. Eur J Nucl Med Mol Imaging 2012;39:337-43.

15. Doot RK, Muzi M, Peterson LM, Schubert EK, Gralow JR, Specht $\mathrm{JM}$, et al. Kinetic analysis of $18 \mathrm{~F}$-fluoride PET images of breast cancer bone metastases. J Nucl Med 2010;51:521-7.

16. Beheshti M, Vali R, Waldenberger P, Fitz F, Nader M, Loidl W, et al. Detection of bone metastases in patients with prostate cancer by $18 \mathrm{~F}$ fluorocholine and $18 \mathrm{~F}$ fluoride PET-CT: a comparative study. Eur J Nucl Med Mol Imaging 2008;35:1766-74.

17. Beheshti M, Vali R, Waldenberger P, Fitz F, Nader M, Hammer J, et al. The use of F-18 choline PET in the assessment of bone metastases in prostate cancer: correlation with morphological changes on CT. Mol Imaging Biol 2009;11:446-54.

18. Reischauer C, Froehlich JM, Koh DM, Graf N, Padevit C, John $\mathrm{H}$, et al. Bone metastases from prostate cancer: assessing treatment response by using diffusion-weighted imaging and functional diffusion maps-initial observations. Radiology 2010;257:523-31. 